\title{
Study on elastoplastic coupling mechanics model of the milled mixture of sugar cane
}

\author{
Qingshan DUAN ${ }^{1}\left(\mathbb{D}\right.$, , Hanling $\mathrm{MAO}^{2 *}$, Hanying $\mathrm{MAO}^{3}$, Zhenfeng $\mathrm{HUANG}^{2}$, Bing $\mathrm{LI}^{2}$, Xinxin $\mathrm{LI}^{2}$
}

\begin{abstract}
At present, the phenomenon of elastoplastic coupling isn't considered in establishing the mechanics model of the milled mixture of sugar cane. In order to describe elastoplastic coupling and yield characteristics, based on uniaxial confined compression tests and direct shear tests, the evolution of the elastic parameters of the solid fiber with void ratio and the plastic deformation, and the plastic mechanics behavior of the solid fiber is described by Modified Drucker-Prager Cap model, the expressions of the parameters of the plastic mechanics model are derived and the corresponding parameters are calculated; and the elastoplastic coupling mechanics model is established. The evolution of the parameters of the model is achieved by the custom subroutine written in Fortran, the numerical simulation of the elastoplastic coupling model is realized by ABAQUS. The results of uniaxial confined compression tests and finite element simulation show that the elastoplastic coupling mechanics model is more accurate than the non-elastoplastic coupling mechanics model to predict the axial pressure. The results provide an important reference for the analysis and understanding of the milling process of sugar cane and the establishment of an accurate mathematical model of the milled mixture of sugar cane.
\end{abstract}

Keywords:the milled mixture of sugar cane; elastoplastic coupling; Modified Drucker-Prager Cap model; mechanics model.

Practical Application: Elastoplastic coupling mechanics model.

\section{Introduction}

The milling process of sugar cane is very complicated, prepared cane are milled into bagasse, the bagasse is then sprayed or soaked with dilute juice and then passed through up to several further mills, in a counter current extraction process, with a further spraying or soaking process occurring before each subsequent mill. In this paper, prepared cane and bagasse are collectively called the milled mixture of sugar cane, which includes solid fiber, juice and air. The milling process involves nonlinear problems, such as large deformation, fluid-solid coupling and strong friction; and then there is no unified description of the mathematical model, mainly based on experimental analysis and empirical data. For accurate analysis of operating parameters and efficiency of the milling process, it is necessary to establish a mathematical model, and the key to the model is the constitutive relationship of the milled mixture of sugar cane (Owen et al., 1995). The milled mixture of sugar cane was treated as porous medium solid-liquid two-phase materials, and researchers had established the constitutive model and theoretical framework of fluid-solid coupling by finite element analysis, and then applied it to the numerical simulation of the milling process (Owen et al., 1995, 1998). Researchers carried out the rapid compression test of prepared cane, estimated the compression index and permeability coefficient of the milled mixture of sugar cane by parameter inversion method of onedimensional model (Kant et al., 2003). Researchers used finite element method to predict the internal energy dissipation of solid substrate deformation and liquid flow during the milling process based on modified Drucker-Prager Cap (DPC) model, but the results need to be tested (Adam \& Loughran, 2005; Loughran \& Kannapiran, 2005). Someone applied the modified Cambridge model of non-associated flow rule and the finite element software to develop the constitutive model to predict the relationship between vertical stress and volumetric strain of primary loading in the milling process (Plaza, 2011a, b). Someone made the uniaxial compression tests and shear tests, employed the parameter estimation package called PEST to determine the material parameters of the milled mixture of sugar cane after multiple milling (Plaza, 2013a, b).

The structural deformation of the milled mixture of sugar cane in the pressing process has been greatly changed, and the structural parameters have been greatly changed. The Poisson ratio of the milled mixture of sugar cane was $0 \sim 0.3$ in the stress range of $0 \sim 3 \mathrm{MPa}$ (Adam \& Loughran, 2005). It was desirable that the Poisson's ratio was 0.15 and Young's modulus was 48MPa (Loughran \& Adams, 1998; Loughran \& Kannapiran, 2005). Poisson ratio was range of 0.1 to 0.18 by analysis of the uniaxial loading-unloading test, and Poisson's ratio was 0.15 and Young's modulus was $20 \mathrm{MPa}$ when the material model was established (Kannpiran, 2003). The finite element simulation of the feeding process was made at the Poisson ratio of 0.3 (Plaza, 2003). The mechanics properties of the milled mixture of sugar cane are affected by factors such as fragmentation, water content and sugarcane varieties. Therefore, material parameters measured by researchers are quite different. And for the same kind of the milled mixture of sugar cane, the elastic parameters 
change with the accumulation of plastic deformation, that is, there is an elastoplastic coupling phenomenon. This leads to the measurement of material parameters of being a range rather than a constant. The characteristics of the milled mixture make it difficult to establish the constitutive relationship. The average values of the parameters were used to establish the constitutive models, that is, constant material parameters cannot fully reflect the mechanics behavior of the milled mixture of sugar cane.

In summary, previous work in the constitutive model of the milled mixture of sugar cane and finite element analysis of the milling process has opened up a new direction for the development of sugarcane milling theory; but failed to fully reflect the mechanics properties and the milling process of the milled mixture of sugar cane. One of the important problems is not considering the elastoplastic coupling caused by the great plastic deformation of the milled mixture of sugar cane in the milling process.

In this paper, at first, the evolution law of elastic plastic parameters of the milled mixture of sugar cane is studied by considering of changes of material parameters. Then, the plastic behavior of the milled mixture is described, and the elastoplastic coupling mechanical model is set up. Finally, the rationality and applicability of the elastoplastic coupling mechanics model of the milled mixture of sugar cane are verified by uniaxial compression tests and finite element analysis. The work provides an important reference for the analysis and understanding of the milling process of sugar cane and the establishment of an accurate mathematical model of the milled mixture of sugar cane.

\section{Method}

\subsection{Materials}

In all of tests, the fiber content of the sample of the $20^{\text {th }}$ Gui-tang is $11.5 \%$ (Nanning, Guangxi, China). The density of the solid fiber is $1530 \mathrm{~kg} / \mathrm{m}^{3}$, the density of the sugarcane juice is $1090 \mathrm{~kg} / \mathrm{m}^{3}$. The length range of the sample is $5 \mathrm{~mm}-10 \mathrm{~mm}$, and the compression ratio is 0.5 .

\subsection{Elastoplastic Coupling Mechanical Model}

\section{Elastic Parameter}

Usually the milled mixture of sugar cane is assumed to be isotropic continuous porous medium, which is saturated solid-liquid two-phase material (Adam \& Loughran, 2005; Li et al., 2017; Loughran \& Kannapiran, 2005; Kannpiran, 2003; Owen et al., 1998). For the isotropic elastic materials, the usual elastic parameters are Young's modulus and Poisson's ratio (Peng et al., 2014). Elastoplastic coupling phenomenon can be characterized from several aspects, such as change of elastic parameters with volumetric strain or equivalent shear strain or void ratio (Eberhardt et al., 1999). Void ratio is the volume ratio of pore space to the solid phase in porous media, and it is one of the important parameters to characterize the structural characteristics of porous media, and its calculation is convenient. In this paper, the relationship between elastic parameters (Young's modulus and Poisson's ratio) and void ratio is used to describe the evolution law of elastic parameters. The value of Young's modulus and Poisson's ratio can be obtained by axial stress and side stress of the sample which measured from uniaxial confined loading-unloading tests (Kannpiran, 2003).

Poisson's ratio is described by equation 1 (Kannpiran, 2003):

$v=\frac{K_{0}}{1+K_{0}}=\frac{\sigma_{x}}{\sigma_{x}+\sigma_{z}}$

where $K_{0}$ is side-stress coefficient, $\sigma_{x}$ is lateral stress, $\sigma_{z}$ is vertical stress.

Young's modulus can be written as equation 2 (Loughran \& Adams, 1998):

$E=\frac{(1+v)(1-2 v)}{1-v} E_{s}$

where $E_{s}$ is the compression modulus of uniaxial confined loading-unloading tests, $E_{s}=\sigma_{z} / \varepsilon_{z}$, where $\varepsilon_{z}$ is vertical strain.

For determining the elastic parameters at different pore ratios, unloading force was set to $3 \mathrm{kN}, 10 \mathrm{kN}$ and $20 \mathrm{kN}$ respectively and three repeated tests were carried out under each unloading force. In order to isolate the effect of the pore pressure of sugarcane juice, many of evenly distributed small holes were set in each surface of the compressed container, and the tests were carried out at the speed of $1 \mathrm{~mm} / \mathrm{min}$ (Kannpiran, 2003).

Void ratio is described by equation 3 (Owen et al., 1995):

$e=\frac{1}{C}\left(1-\frac{\rho_{f}}{\rho_{j}}\right)+\frac{1}{f C}\left(\frac{\rho_{f}}{\rho_{j}}\right)-1$

where $f$ is the fiber content, $\rho_{f}$ is the density of the solid fiber, $\rho_{j}$ is the density of the sugarcane juice, $C$ is the compression ratio. Compression ratio is usually used to characterize the compression degree of the milled mixture, can be calculated by equation 4 (Kannpiran, 2003).

$C=\frac{h_{n g}}{h}$

where $h$ is the present height of the sample, $h_{n g}$ is the height of the sample with no pore gas and can be calculated by equation 5 (Kannpiran, 2003).

$h_{n g}=\frac{m_{c}}{A_{p}}\left(\frac{f}{\rho_{f}}+\frac{1-f}{\rho_{j}}\right)$

where $m_{c}$ is the sample weight, which is $2.275 \mathrm{~kg}$; $A_{p}$ is the cross-sectional area, which is $120 \mathrm{~mm} \times 120 \mathrm{~mm}$.

\section{Plastic constitutive model}

Previous studies have shown that the plastic deformation and yield characteristics of the solid fiber have the following characteristics (Adam \& Loughran, 2005; Loughran \& Kannapiran, 2005; Kannpiran, 2003; Owen et al., 1998; Plaza, 2011a, b; 2012, 2013a, 2013b; Plaza et al., 2014):

(a) Exhibits large plastic volumetric strains.

(b) Has a non-linear plastic strain hardening relation. 
(c) Is highly compressible and yields under hydrostatic pressure.

(d) A marked shear failure and exhibiting dilatancy.

According to the characteristics (a) and (c), the plastic model and yield conditions developed by the metal deformation mechanism can be excluded, because the premise of their establishment is the volume incompressibility and no hydrostatic pressure. The solid fiber can resist shear force under low vertical or zero pressure which shows there is a cohesive force (Plaza et al., 2014). DPC model can describe tension (component of a cohesive force), modified DPC model can be modeled on tension. Modified DPC model makes the simulation of the milling process have good numerical robustness and is deemed to be the most capable of reflecting the mechanical behavior of the milled mixture of sugar cane (Plaza et al., 2014). Therefore, modified DPC model is used to describe the plastic behavior of the solid fiber.

As in Figure 1, yield surface of the modified DPC model is made up of shear failure surface, smooth transition surface and cap surface. Shear failure surface is described by equation 6 (Han et al., 2008).

$$
F_{s}=q-p \tan \beta-d=0
$$

where $\beta$ is internal friction angle, $d$ is cohesive pressure, $p$ is Mises equivalent shear stress, and $q$ is equivalent hydrostatic pressure.

Cap surface is described by equation 7 .

$F_{c}=\sqrt{\left(p-p_{a}\right)^{2}+\left[\frac{R q}{1+\alpha-\frac{\alpha}{\cos \beta}}\right]^{2}}-R\left(d+p_{a} \tan \beta\right)=0$

where $R$ is the cap of eccentricity and controls parameters of cap shape, $\alpha$ is the constant controlling shape transition zone, $p_{a}$ is the intersection of smooth transition surface and cap surface, which can be calculated by equation 8 .

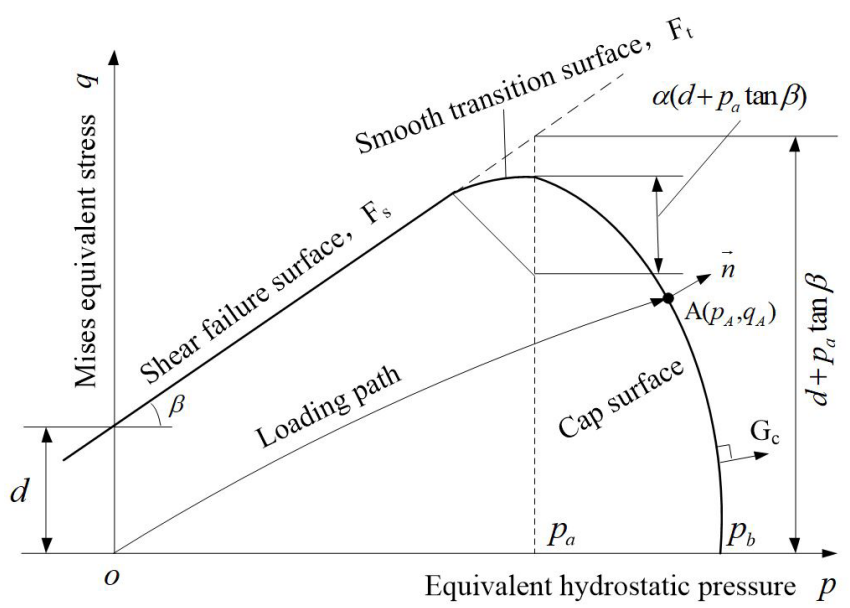

Figure 1. Yield surface of the modified Drucker-Prager Cap model.
$p_{a}=\frac{p_{b}-R d}{1+R \tan \beta}$

where $p_{b}$ is hydrostatic compression yield stress which controls the cap size, is also the intersection of hydrostatic pressure and the cap surface.

The plastic potential function on the cap surface is described by equation 9 .

$G_{c}=\sqrt{\left(p-p_{a}\right)^{2}+\left[\frac{R q}{1+\alpha-\frac{\alpha}{\cos \beta}}\right]^{2}}$

\section{Plastic Parameters}

Plastic parameters of the modified DPC model are 6 parameters of the yield surface, friction angle $(\beta)$, cohesive pressure $(d)$ and cap surface parameters $\left(R, p_{a}, p_{b}, \alpha\right)$.

\section{Friction angle and cohesive pressure}

Friction angle and cohesion pressure can be obtained by the conventional triaxial tests or direct shear tests. Previous studies pointed out that the conventional triaxial tests do not destroy the solid fiber and the friction angle and cohesive pressure are small (Adam \& Loughran, 2005; Loughran \& Kannapiran, 2005; Kannpiran, 2003; Owen et al., 1998). The friction angle and cohesive pressure of Mohr-Coulomb model can be gotten by direct shear test. The friction angle and cohesive pressure of the modified DPC model can be calculated by equations 10 and 11, respectively (Han et al., 2008).

$\beta=\arctan \frac{6 \sin \phi}{3-\sin \phi}$

$d=2 c \frac{\cos \phi}{1-\sin \phi}$

At shearing speed of $0.8 \mathrm{~mm} / \mathrm{min}$, direct shear tests were carried out under pressure in $100 \mathrm{kPa}, 200 \mathrm{kPa}, 300 \mathrm{kPa}$ and $400 \mathrm{kPa}$, respectively. The sample weight is $130 \mathrm{~g}$. The results of the tests showed that the shear strength has a good linear relationship with the vertical stress. That is, friction angle and cohesion pressure are constant parameters. The friction angle and cohesive pressure of the modified DPC model are $51.68^{\circ}$ and $36.284 \mathrm{kPa}$, respectively.

\section{Cap surface parameters}

Four parameters are required to determine the shape of the cap surface. By the method of Han L H and Rui Z (Han et al., 2008; Rui et al., 2013), cap surface parameters were determined by uniaxial confined compression tests. $\alpha$ is zero in this model which indicates that there is no smooth transition zone; and the state of the cap surface on the right side indicates that the volume is compressed, and the cap surface will not be softened. $p_{a}$ and $\mathrm{R}$ can be determined by analyzing the stress state of the loading point on the cap surface. As shown in Figure 1, the 
loading path $\mathrm{OA}$ is drawn in space. When the loading point falls on the cap surface it will yield (A), which is, cap surface equation 7 is established.

The association flow rule is used in the cap region, and the plastic strain rate can be expressed as $\dot{\varepsilon}_{i j}^{p}=\dot{\lambda} \frac{\partial G_{c}}{\partial \sigma_{i j}}=\dot{\lambda} \frac{\partial F_{c}}{\partial \sigma_{i j}}$. Assuming that the metal container used in tests is rigid, the lateral strain rate of point $\mathrm{A}$ can be written as equation 12 .

$\dot{\varepsilon}_{x}^{p}=\dot{\varepsilon}_{y}^{p}=\left.\dot{\lambda} \frac{\partial G_{c}}{\partial \sigma_{x}}\right|_{\left(p_{A}, q_{A}\right)}=0$

Where $p_{A}$ is Mises equivalent shear stress of point $\mathrm{A}$, and $q_{A}$ is equivalent hydrostatic pressure of point $\mathrm{A}, \dot{\lambda}$ is a positive instantaneous constant, so

$\left.\frac{\partial G_{c}}{\partial \sigma_{x}}\right|_{\left(p_{A}, q_{A}\right)}=0$

Put equation 9 into equation 13 , equation 14 can be obtained.

$\left.2\left(p_{A}-p_{a}\right) \frac{\partial p}{\partial \sigma_{x}}\right|_{\left(p_{A}, q_{A}\right)}+\left.2 \frac{R^{2} q}{\left(1+\alpha-\frac{\alpha}{\cos \beta}\right)^{2}} \frac{\partial q}{\partial \sigma_{x}}\right|_{\left(p_{A}, q_{A}\right)}=0$

In uniaxial confined compression tests, $p=-\left(\sigma_{z}+2 \sigma_{x}\right) / 3$, $q=\left|\sigma_{z}-\sigma_{x}\right|$, so $R$ can be written as equation 15 .

$R=\sqrt{\frac{2(1+\alpha-\alpha / \cos \beta)^{2}}{3 q_{A}}\left(p_{A}-p_{a}\right)}$

Let $M=(1+\alpha-\alpha / \cos \beta)^{2} \tan \beta$, parameter $p_{a}$ can be obtained by equation 7 and equation 15 and written as equation 16 .

$p_{a}=-\frac{3 q_{A}+4 d M}{4 M \tan \beta}+\frac{\sqrt{9 q_{A}^{2}+24 d q_{A} M+8 M\left(3 p_{A} q_{A}+2 q_{A}^{2}\right) \tan \beta}}{4 M \tan \beta}$

From equation $8, p_{b}$ can be written as equation 17 .

$p_{b}=p_{a}(1+R \tan \beta)+R d$

The hardening/softening law of the modified DPC model can be described by the relationship between hydrostatic pressure on cap surface and the corresponding inelastic strain; and the relationship can be determined by piece-wise linear function. Only considering plastic volumetric strain, $p_{b}=f\left(\varepsilon_{v}^{p l}\right), \varepsilon_{v}^{p l}$ is the plastic volumetric strain can be expressed as equation 18 (Chtourou et al., 2002a, b).

$\varepsilon_{v}^{p l}=\ln \left(\frac{\rho}{\rho_{0}}\right)$

In equation $18, \rho$ is the current density, $\rho_{0}$ is the initial density. In the tests, the cross-sectional area of the specimen is constant, so the plastic volume strain can be expressed as $\varepsilon_{v}^{p l}=\ln \left(\frac{h_{0}}{h}\right), h_{0}$ is the initial height of the sample.

At this point, all the parameters of the modified DPC model have been determined.

\subsection{Simulation of elastoplastic coupling mechanical model}

The finite element analysis software ABAQUS has been widely applied in the numerical calculation of the mechanical structure, materials and thermodynamics (Fan \& Guo, 2015; Qin et al., 2017; Yan et al., 2016). This paper uses it to establish a mechanical model. The evolution of the parameters $E, v$ and $R$ in the mechanical model is realized by user defined field (USDFLD) subroutine written in Fortran. The USDFLD subroutine can define field variable $f_{i}$ in the integral point of each unit, and the material parameters can be defined as the function of the field variable. Here, the elastic parameters evolve with the change of void ratio. Therefore, the field variable is defined as void ratio, that is, $f_{i}=e_{i}$, which is used to update the current material property of each time step.

Elastoplastic coupling calculation process is shown in Figure 2. At each time step, the subroutine USDFLD calculates the void ratio, the void ratio is assigned to a state variable, the current material parameters will be determine from the experimental calibration of material parameters table $\left(E_{i}, v_{i}, R_{i}, e_{i}\right)$ based on the state variables (void ratio). The updated material parameters are used to calculate stress, strain, pore ratio, etc. of the next time step. When the stress (strain) increment of the time step is small, the error of this treatment is very small (Yang et al., 2013).

\section{Results and discussion}

\subsection{Evolution law of elastic parameters}

In uniaxial confined loading-unloading tests, the elastic recovery is very small at each unloading process, as shown in Figure 3. Therefore, it is assumed that the void ratio of a single unloading process remains constant.

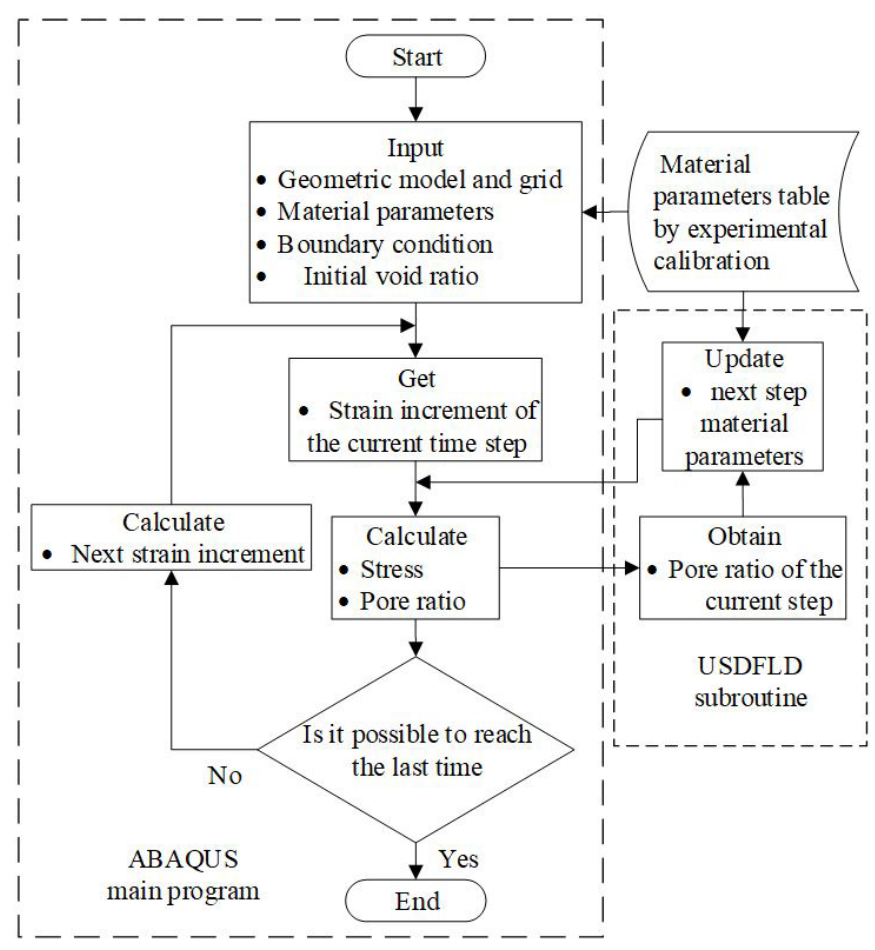

Figure 2. Elastoplastic coupling calculation process. 
As seen in Figure 4, the growth rate of Young's modulus and Poisson's ratio is getting faster and faster with decreasing of void ratio; but the rates aren't same.

\subsection{Evolution law of parameters of plastic model}

For the milled mixture of sugar cane, it is more suitable that the strain is zero when the compression ratio is 0.8 (Kannpiran, 2003). Parameter $R$ is calculated by the equations 15 and 16 .

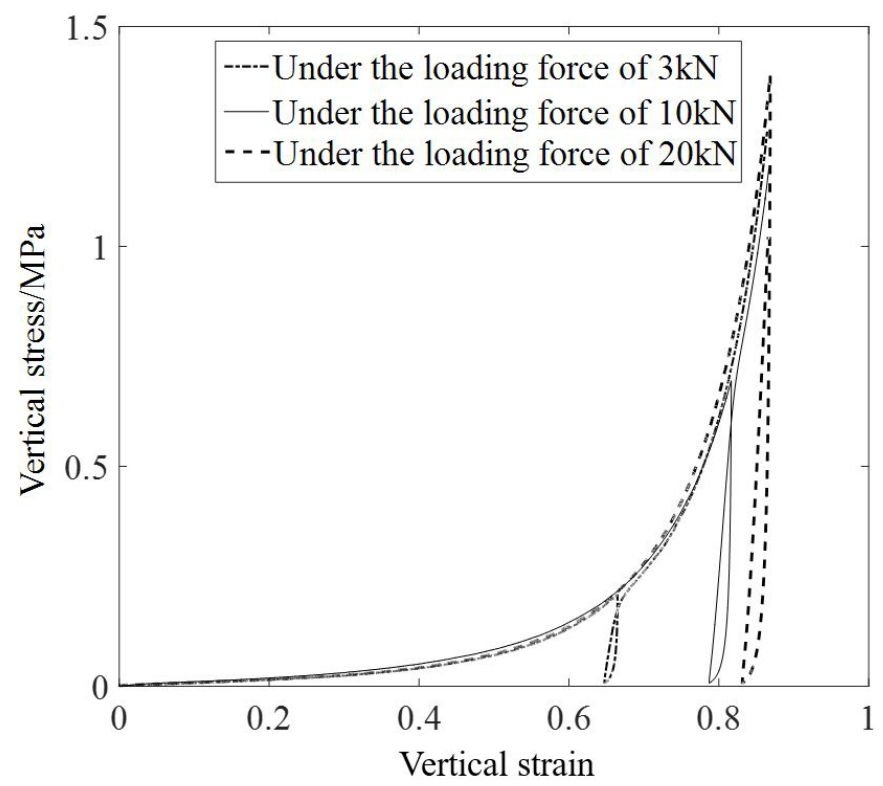

Figure 3. Vertical stress-strain curves in uniaxial confined loading-unloading tests.

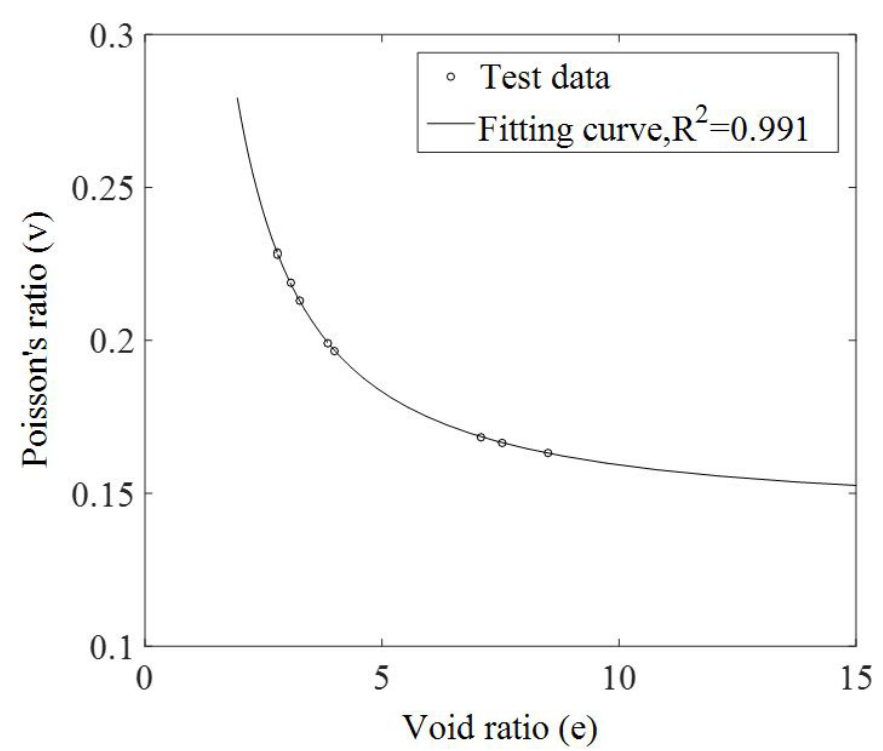

(a)
As shown in Figure 5(a), parameter R gradually increases with the decreasing of void ratio when the void ratio is less than 5.365, but it is opposite when the void ratio is greater than 5.365. $p_{b}$ is obtained by equation (19)-(22). The hardening law of the modified DPC model is the evolution of $p_{b}$ with the plastic volume strain $\left(\varepsilon_{v}^{p l}\right)$, as shown in Figure 5(b). With the increasing of $\varepsilon_{v}^{p l}$, the growth rate of $p_{b}$ is getting faster and faster.

According to the estimated parameters, the evolution process of the cap surface in the $p-q$ stress space is plotted; the stress paths of the uniaxial confined compression tests and consolidated-drained triaxial tests are also drawn in the $p-q$ stress space, as shown in Figure 5(c). With the increase of stress $\left(p_{b}\right)$, the plastic strain of the solid fiber is increasing. The stress paths of the uniaxial confined compression tests and consolidated-drained triaxial tests change below the shear yield surface, and there is no shear failure. With the increasing of stress, the stress path constantly passes through the new yield surface, that is, there is continuous hardening, which is consistent with the experimental phenomenon.

\subsection{Elastoplastic coupling analysis}

Static analysis of uniaxial confined compression tests

In the statics analysis, the effect of pore pressure is not calculated, and only the constitutive model of the solid fiber is calculated. The influence of sugarcane juice can be eliminated in statics analysis. The mechanical behavior of the solid fiber is simulated and compared with uniaxial static compression test to verify the rationality and applicability of elastoplastic coupling model. According to the experimental conditions of uniaxial confined compression tests, the corresponding finite element model was established by the finite element software

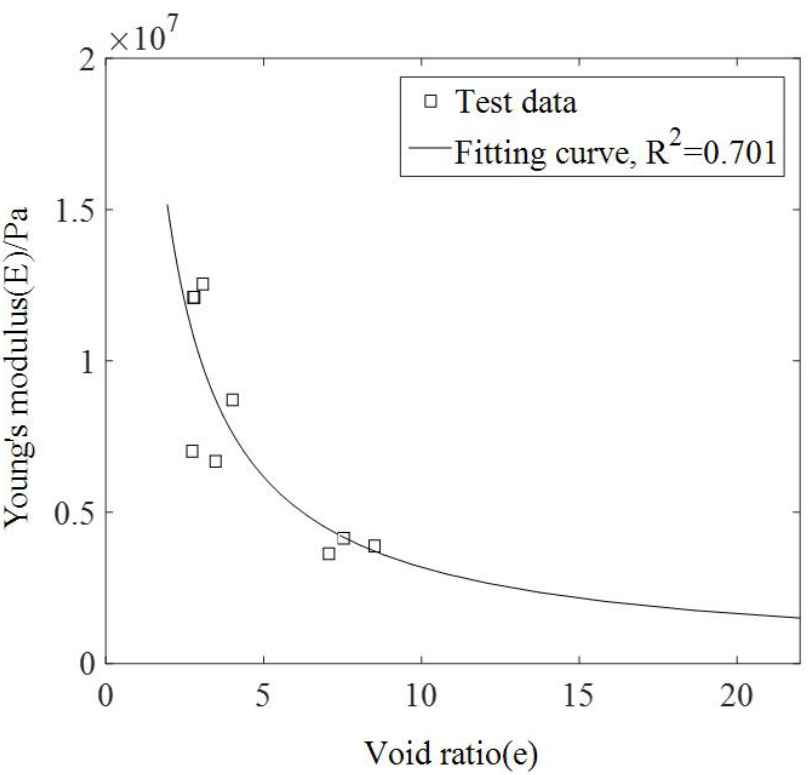

(b)

Figure 4. Evolution of Poisson's ratio (a) and Young's modulus (b). 


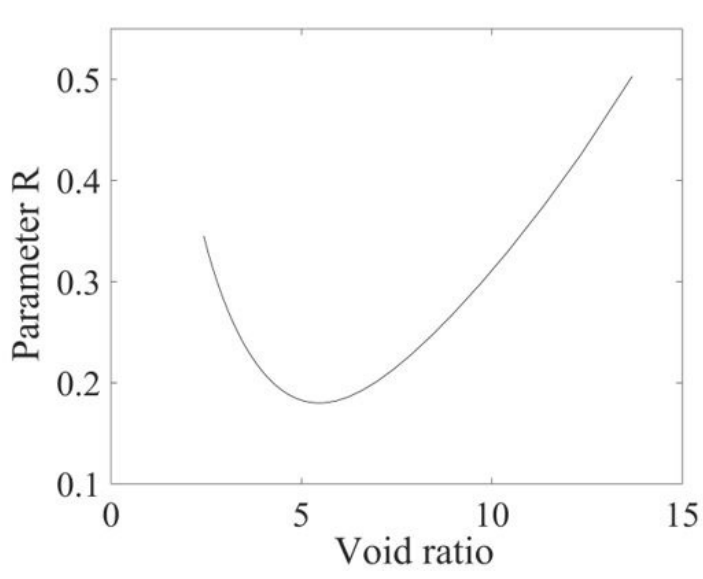

(a)

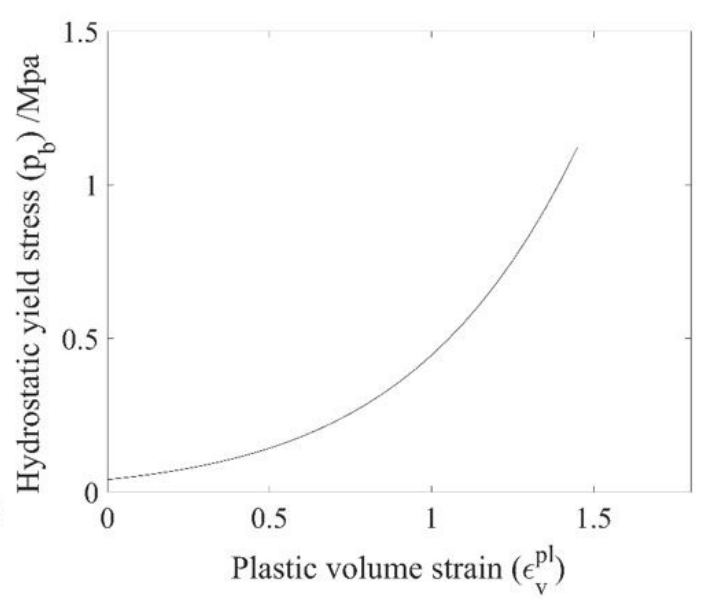

(b)

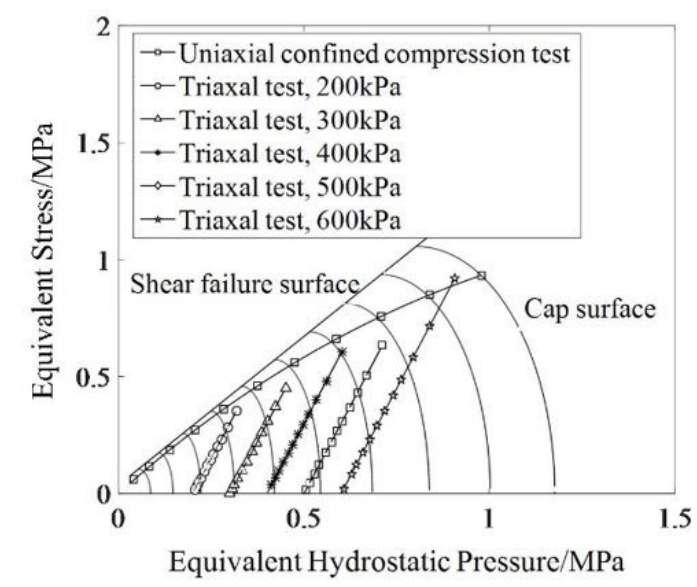

(c)

Figure 5. Evolution of parameter $R$ (a) and $p_{b}$ (b) of plastic model and yield surface (c).

ABAQUS, and the finite element analysis was carried out to obtain the effective stress and axial pressure of the solid fiber. Mises equivalent stress and axial pressure of the solid fiber is evenly distributed, because there is no effect of sugarcane juice, that is, the fluid-solid coupling between the solid fiber and sugarcane juice is not considered.

\section{Error analysis}

Uniaxial confined compression tests are carried out at the speed of $1 \mathrm{~mm} / \mathrm{min}$ to verify the rationality and effectiveness of the mechanical model. The relationship between the axial force and the compression ratio at the uniaxial confined compression test, the elastoplastic coupling model and the non-elastoplastic coupling model (the mean value of the measured values of the elastoplastic parameters) is shown in Figure 6(a). Obviously, in three axial forces, axial forces at the uniaxial confined compression tests are the biggest and axial forces at the non-elastoplastic coupling model are the smallest at the same compression ratio. Compared with the non-elastoplastic coupling model, the elastoplastic coupling model can more accurately predict the axial force in the test.

The relative errors between the axial force calculated by the elastoplastic coupling model and those obtained from the tests are shown in Figure 6(b). When compression ratio is relatively small (less than 1) the relative errors are large (5\% 16\%); probably because the solid fiber is in loose condition, there are some differences with the hypothesis of the solid-liquid two-phase saturated isotropic continuum material, resulting in a big difference between the predicted value of the model and the experimental data. When compression ratio exceeds 1 the simulation value is about $5 \%$ smaller than test data, probably because the tests failed to eliminate the effect of pore pressure completely, and the effect of static simulation can eliminate the pore pressure completely. In the milling process of sugar cane, the range of compression ratio is in $[1.0,3.0]$. Therefore, the elastoplastic coupling mechanical model of the milled mixture of sugar cane is applicable and reasonable in the milling process of sugar cane. 


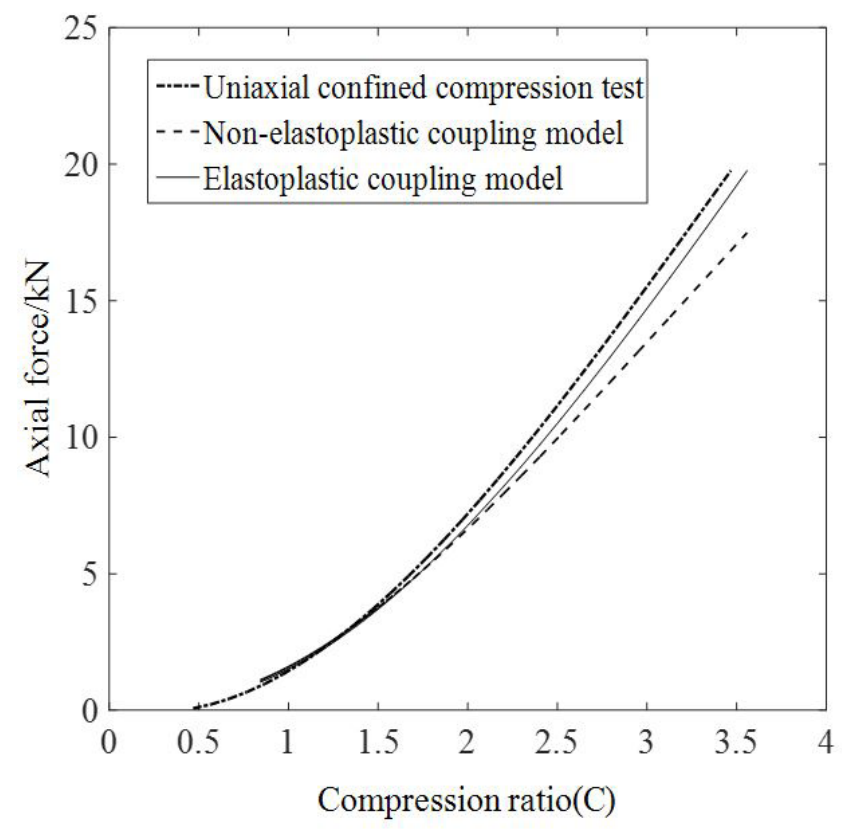

(a)

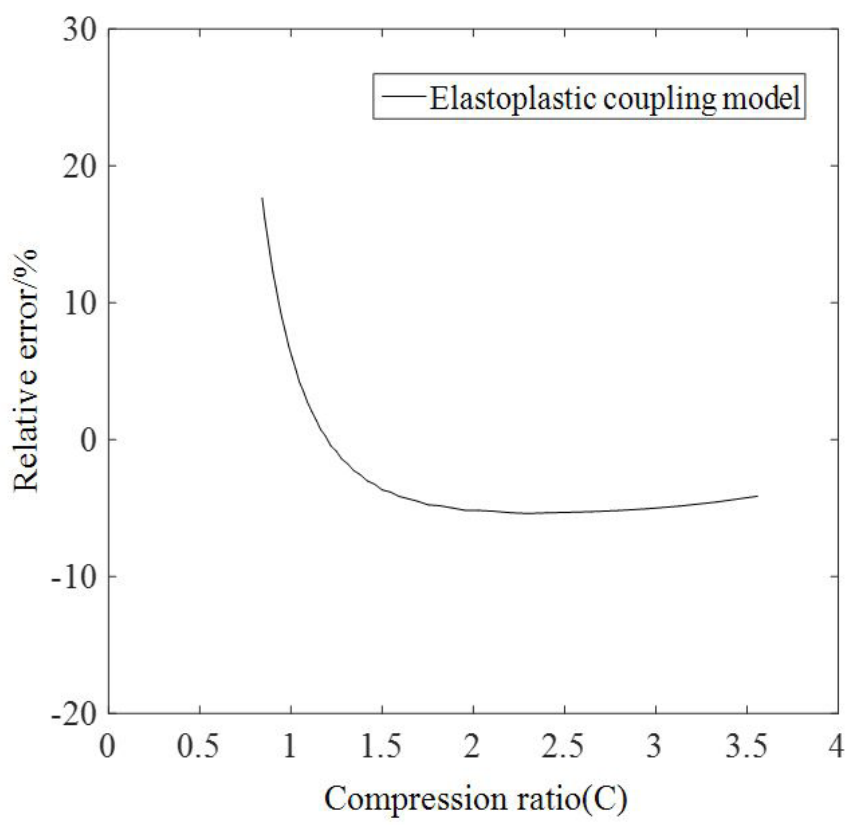

(b)

Figure 6. Axial forces for simulation of coupling model and uniaxial confined compression test (a) and the relative error in elastoplastic coupling model (b).

\section{Conclusion}

In view of elastoplastic coupling phenomenon in the milling process, a mechanical model of elastoplastic coupling of the milled mixture of sugar cane was established by modified DPC model and parameters evolution and verified by uniaxial compression test and finite element analysis. Considering the variation of elastic parameters with plastic deformation, combined with the characteristics of porous media of the solid fiber, the evolution rule of elastic parameters with void ratio was determined according to the results of uniaxial confined loading-unloading tests, the growth rate of Young's modulus and Poisson's ratio was getting faster and faster with decreasing of void ratio; but the rates weren't same. The parameter equation of the modified DPC model was derived and the parameters were established according to direct shear tests and uniaxial confined compression tests. Parameter $\mathrm{R}$ gradually increases with the decreasing of void ratio when the void ratio is less than 5.365 , but it is opposite when the void ratio is greater than 5.365; with the increasing of $\varepsilon_{v}^{p l}$, the growth rate of $p_{b}$ is getting faster and faster. Through the user-defined platform in ABAQUS, the elastoplastic coupling model is established, and uniaxial static compression test is simulated. The simulation results show that the elastoplastic coupling model can more accurately reflect the mechanical properties of the solid fiber than the non-elastoplastic coupling model.

\section{Acknowledgements}

This research was supported by Guangxi Natural Science Foundation (Grant No. 2018GXNSFAA138206), the manufacturing system and advanced manufacturing technology of Guangxi key laboratory project (Contact No. 14-045-15S05).

\section{References}

Adam, C., \& Loughran, J. (2005). The effect of blanket thickness on extraction energy in sugarcane rolling mills: a finite element investigation. Biosystems Engineering, 92(2), 255-263. http://dx.doi. org/10.1016/j.biosystemseng.2005.07.004.

Chtourou, H., Gakwaya, A., \& Guillot, M. (2002a). Modeling of the metal powder compaction process using the cap model. Part II: Numerical implementation and practical applications. International Journal of Solids and Structures, 39(4), 1077-1096. http://dx.doi. org/10.1016/S0020-7683(01)00256-6.

Chtourou, H., Guillot, M., \& Gakwaya, A. (2002b). Modeling of the metal powder compaction process using the cap model. Part I. Experimental material characterization and validation. International Journal of Solids and Structures, 39(4), 1059-1075. http://dx.doi. org/10.1016/S0020-7683(01)00255-4.

Eberhardt, E., Stead, D., \& Stimpson, B. (1999). Quantifying progressive pre-peak brittle fracture damage in rock during uniaxial compression. International Journal of Rock Mechanics and Mining Sciences, 36(3), 361-380. http://dx.doi.org/10.1016/S0148-9062(99)00019-4.

Fan, J. L., \& Guo, X. L. (2015). Numerical simulation on elastic-plastic fatigue crack growth behavior. Journal of Mechanical Engineering, 51(10), 33-40. http://dx.doi.org/10.3901/JME.2015.10.033.

Han, L. H., Elliott, J. A., Bentham, A. C., Mills, A., Amidon, G. E., \& Hancock, B. C. (2008). A modified Drucker-Prager Cap model for die compaction simulation of pharmaceutical powders. International Journal of Solids and Structures, 45(10), 3088-3106. http://dx.doi. org/10.1016/j.ijsolstr.2008.01.024.

Kannpiran, A. (2003). Computational and experimental modeling of the crushing of prepared sugar cane ( $\mathrm{PhD}$ thesis), James Cook University, Townsville. 
Kant, G. A., McKenzie, N. J., \& Hogarth, D. M. (2003, May 06-09). A simple test for determining some important material properties for bagasse. In Australian Society of Sugar Cane Technologists, Proceedings of 2003 Conference of the Australian Society of Sugar Cane Technologists. Townsville, Australia: Watson Ferguson and Co.

Li, B., Li, X. X., Mao, H. L., \& Huang, Z. F. (2017). Fuid-solid Coupling Analysis of Sugarcane Crushing Based on Porous Media. Journal of Mechanical Engineering, 53(12), 192-200. http://dx.doi.org/10.3901/ JME.2017.12.192.

Loughran, J. G., \& Adams, C. J. (1998, May 06-09). Properties of prepared cane for computational crushing models. In Australian Society of Sugar Cane Technologists, Proceedings of the 1998 Conference of the Australian Society of Sugar Cane Technologists. Townsville, Australia: ASSCT.

Loughran, J. G., \& Kannapiran, A. (2005). Three-dimensional simulation of the rolling of a saturated fibro-porous media. Finite Elements in Analysis and Design, 42(1), 90-104. http://dx.doi.org/10.1016/j. finel.2005.05.006.

Owen, D. R. J., Souza Neto, E. A., Zhao, S. Y., Perić, D., \& Loughran, J. G. (1998). Finite element simulation of the rolling and extrusion multi-phase materials-Application to the rolling of prepared sugar cane. Computer Methods in Applied Mechanics and Engineering, 151(3), 479-495. http://dx.doi.org/10.1016/S0045-7825(97)00173-4.

Owen, D., Zhao, S. Y., \& Loughran, J. G. (1995). Application of porous media mechanics to the numerical simulation of the rolling of sugar cane. Engineering Computations, 12(3), 281-302. http://dx.doi. org/10.1108/02644409510799596.

Peng, J., Rong, G., Cai, M., Wang, X., \& Zhou, C. (2014). An empirical failure criterion for intact rocks. Rock Mechanics and Rock Engineering, 47(2), 347-356. http://dx.doi.org/10.1007/s00603-012-0355-6.

Plaza, F. (2003, May 6-9). Finite element modelling of a pressure feeder using direct shear test measurements. In Proceedings of the 2003 Conference of the Australian Society of Sugar Cane Technologists. Townsville, Australia: ASSCT.

Plaza, F. (2011a). A further step in the modelling of the mechanical behaviour of bagasse. International Sugar Journal, 113(1351), 505-508.
Plaza, F. (2011b). An additional step towards modelling the mechanical behaviour of sugar cane bagasse. In Proceedings of the 33rd Annual Conference of the Australian Society of Sugar Cane Technologists. Queensland: ASSCT.

Plaza, F. (2012). Modelling of the mechanical behaviour of heavily over-consolidated bagasse. In Proceedings of the 34th Annual Conference of the Australian Society of Sugar Cane Technologists. Cairns, Australia: ASSCT.

Plaza, F. (2013a). Determining the material properties for heavily overconsolidated bagasse through parameter estimation. In Proceedings of the 28th International Society of Sugar Cane Technologists Congress. Brazil: ASSCT.

Plaza, F. (2013b). Towards a multi-element simulation of heavily overconsolidated bagasse using a material subroutine. In Proceedings of the 35th Conference of the Australian Society of Sugar Cane Technologists, Townsville: ASSCT.

Plaza, F., Kent, G., Rackemann, D., \& Stephens, D. (2014). Review and future options for computer modelling in the sugar industry. International Sugar Journal, 116(1390), 740-746.

Qin, F., Li, Y., Qi, H., \& Ju, L. (2017). Advances in compact manufacturing for shape and performance controllability of large-scale components-a review. Chinese Journal of Mechanical Engineering, 30(1), 7-21. http:// dx.doi.org/10.3901/CJME.2016.1102.128.

Rui, Z., Zhang, L., He, B., \& Liu, Y. (2013). Numerical simulation of residual stress field in 395 green power metallurgy compacts by modified Drucker - Prager Cap model. Transactions of 396 Nonferrous Metals Society of China, 23(8), 2374-2382.

Yan, Y., Wang, H., Li, Q., \& Guan, Y. (2016). Finite element simulation of flexible roll forming with supplemented material data and the experimental verification. Chinese Journal of Mechanical Engineering, 29(2), 342-350. http://dx.doi.org/10.3901/CJME.2015.0824.106.

Yang, F. J., Zhou, H., Xiao, H. B., Zhang, C. Q., \& Zhang, K. (2013). Research on confining pressure effect of elastic parameters of marble and its elasto-plastic coupling model. Yantu Lixue, 34(6), 1613-1620. http://dx.doi.org/10.16285/j.rsm.2013.06.008. 